\title{
Foot and leg conformation traits have a small effect on genomic predictions of claw disorders in Norwegian Red cows
}

\author{
C. Ødegård, ${ }^{*} \dagger^{1} M$. Svendsen, ${ }^{*}$ and $B$. Heringstad ${ }^{*} \dagger$ \\ *Geno Breeding and A. I. Association, PO Box 5003, NO-1432 Ås, Norway \\ †Department of Animal and Aquacultural Sciences, Norwegian University of Life Sciences, PO Box 5003, NO-1432 Ås, Norway
}

\begin{abstract}
The aim of this study was to evaluate whether the predictive correlation of genomic breeding values (GEBV) for claw disorders increased by including genetically correlated traits as additional information in the analyses. Predictive correlations of GEBV for claw disorders were calculated based on claw disorders only and by analyzing claw disorders together with genetically correlated foot and leg conformation traits. The claw disorders analyzed were corkscrew claw (CSC); infectious claw disorder, including dermatitis, heel horn erosion, and interdigital phlegmon; and laminitis-related claw disorder, including sole ulcer, white line disorder, and hemorrhage of sole and white line. The foot and leg conformation traits included were hoof quality, foot angle, rear leg rear view new, and rear leg rear view old. The data consisted of 183,728 daughters with claw health records and 421,319 daughters with foot and leg conformation scores. A $25 \mathrm{~K} / 54 \mathrm{~K}$ single nucleotide polymorphism (SNP) data set containing 48,249 SNP was available for the analyses. The number of genotyped sires with daughter information in the analyses was 1,093 including claw disorders and 3,111 including claw disorders and foot and leg conformation traits. Predictive correlations of GEBV for CSC, infectious claw disorder, and laminitis-related claw disorder were calculated from a 10-fold cross-validation and from an additional validation set including the youngest sires. Only sires having daughters with claw health records were in the validation sets, thus increasing the reference population when adding foot and leg conformation traits. The results showed marginal improvement in the predictive correlation of GEBV for CSC when including hoof quality and foot angle, both in 10-fold cross-validation (from 0.35 to 0.37 ) and in the validation including the youngest sires (from 0.38 to 0.49 ). For infectious claw disorder and laminitis-related claw
\end{abstract}

Received December 3, 2014.

Accepted February 16, 2015.

${ }^{1}$ Corresponding author: cecilie.odegard@nmbu.no disorder, including foot and leg conformation traits had no effect on the predictive correlation of GEBV. Claw disorders are novel traits with a limited amount of historical data and, therefore, a small reference population. Increasing the reference population by including sires with daughter information on foot and leg conformation traits had small effect on the predictive correlation of GEBV. However, the small increase in predictive correlation of GEBV for CSC shows a possible gain when including moderate to high genetically correlated traits.

Key words: dairy cow, genomic breeding value, claw health, Norwegian Red

\section{INTRODUCTION}

Claw health is important for animal welfare (Bruijnis et al., 2012) and for dairy production economy (Bruijnis et al., 2010) by influencing milk production (Sogstad et al., 2007), fertility, and production diseases (Sogstad et al., 2006). In Norway, claw health status at claw trimming has been reported to the Norwegian Dairy Herd Recording System since 2004. The frequencies of claw disorders in Norwegian Red are in general low, ranging from $0.2 \%$ (interdigital phlegmon) to $10 \%$ (corkscrew claw, CSC) (Ødegård et al., 2013). Heritabilities (on the underlying scale) of claw disorders in different breeds ranged from 0.06 to 0.23 (e.g., Swalve et al., 2008; Buch et al., 2011; Ødegård et al., 2013). Estimated genetic correlations between claw disorders and foot and leg conformation traits are low to moderate but with some variations between studies and breeds (e.g., van der Waaij et al., 2005; Uggla et al., 2008; Ødegård et al., 2014a). Ødegård et al. (2014a) showed that 7 out of 15 genetic correlations between claw disorders and foot and leg conformation traits in Norwegian Red were significantly different from zero, ranging from -0.86 to 0.26 . The strongest genetic correlation was found between CSC from claw trimming and hoof quality (HQ) from conformation score, which are supposed to measure the same trait. Hoof quality has the same definition as CSC but is recorded by breeding advisors when the cow is standing. 
Genomic selection has a huge potential to increase genetic gain (Meuwissen et al., 2001). In the selection program for Norwegian Red, the accuracy of genomic breeding values (GEBV) is low compared with the accuracy of EBV from progeny testing, especially for health and fertility traits (e.g., Luan et al., 2009; Svendsen et al., 2013; Haugaard et al., 2014). The accuracy of GEBV, calculated as the correlation between EBV and GEBV, ranged from 0.16 (stillbirth, direct) to 0.77 (slaughter classification) in Norwegian Red (Svendsen et al., 2013). Similar results were found in other studies, where production traits showed higher accuracy or reliability of GEBV than functional traits (e.g., Solberg et al., 2011; Gao et al., 2013; Zhou et al., 2014). With novel traits such as claw disorders, the historical data and reference population is limited, making genomic selection challenging. One way to improve the accuracy of GEBV is to increase the size of the reference population (e.g., Hayes et al., 2009) by including genetically correlated traits. Svendsen et al. (2013) calculated relatively high accuracy of GEBV for foot and leg conformation traits, ranging from 0.60 to 0.71 . Foot and leg conformation traits that are genetically correlated with claw disorders may contribute additional information and thereby improve the predictive correlation of GEBV for claw disorders.

The study had 2 aims. (1) The first aim was to conduct genomic analyses of claw disorders in Norwegian Red, to evaluate predictive correlation of GEBV for CSC, infectious claw disorder (INF), and laminitis-related claw disorder (LAM). (2) The second aim was to examine whether including genetically correlated foot and leg conformation traits in the analyses increased the genomic prediction of CSC, INF, and LAM.

\section{MATERIALS AND METHODS}

\section{Data and Editing}

Claw Health. Claw health status at claw trimming reported to the Norwegian Dairy Herd Recording System from 2004 to 2013 was included in the analyses. Nine different claw disorders were recorded at claw trimming: CSC, dermatitis, heel horn erosion, interdigital phlegmon, sole ulcer, white line disorder, hemorrhage of sole and white line, lameness, and acute trauma. Cows with no claw disorders present at claw trimming were recorded as having normal claws. Based on frequencies of and genetic correlations among claw disorders (Ødegård et al., 2013), 1 claw disorder and 2 groups of claw disorders were included in the analyses: CSC, INF (including dermatitis, heel horn erosion, and interdigital phlegmon), and LAM (including sole ulcer, white line disorder, and hemorrhage of sole and white line). A cow was defined as unaffected (0) or affected (1) for CSC, INF, and LAM in each parity in which the cow had at least one record from claw trimming. Claw-trimming practice varies among herds; in some herds all cows are routinely claw trimmed once a year, whereas in others, claw trimming is carried out occasionally on selected cows only. In Norway, claw trimming is performed by professional claw trimmers (with certification), other claw trimmers (working as claw trimmers without certification), farmers, or others (e.g., veterinarians). More details of claw health data in Norway can be found in the study by Ødegård et al. (2013).

Data were edited as described by Ødegård et al. (2013): only lactating cows with recorded claw health records, daughters of Norwegian Red AI sires, cows with at least one claw health record in a parity, and herds reporting at least $10 \%$ or 10 normal claw records from 2004 to 2013 (this to exclude herds reporting only affected cows) were included in the analyses. Sires were required to have at least 30 daughters with claw health records. Data included in the analyses consisted of 281,835 claw health records from 183,728 daughters of 1,093 sires, and the number of herds was 6,976 . The mean frequencies of CSC, INF, and LAM after editing were 11,7 , and $8 \%$, respectively.

Foot and Leg Conformation. Foot and leg conformation was scored on first-parity cows and reported to the Norwegian Dairy Herd Recording System. Breeding advisors, at present about 50 people, score 4 defined foot and leg conformation traits, $\mathrm{HQ}$, foot angle (FANG), rear leg rear view (RLRV), and rear leg side view, on a linear scale from 1 to 9 . The definition and optimal value of RLRV changed in 2010, hence 2 traits were defined: RLRV new ( RLRV_N) and RLRV old (RLRV_O). The optimum values were 9 for HQ; 8 for RLRV_N; and 5 for FANG, RLRV_O, and rear leg side view. Based on results from Ødegård et al. (2014a), the foot and leg conformation traits included in the analyses were HQ, FANG, RLRV_N, and RLRV_O (these traits had a genetic correlation significantly different from zero for at least one claw disorder). Foot and leg conformation score was available for HQ from 1996 to 2013, FANG from 1987 to 2013, RLRV_N from 2010 to 2013, and RLRV_O from 1987 to 2009.

Data were edited as described in Ødegård et al. (2014a): only daughters of Norwegian Red AI sires; cows with age at first calving between 18 and 33 mo; and cows that were conformation scored within a defined time period (months after calving) were included. The data analyzed consisted of 305,195 daughters of 2,183 sires for HQ; 421,319 daughters of 3,111 sires for FANG; 52,330 daughters of 571 sires for RLRV_N; and 368,834 daughters of 2,710 sires for RLRV_O. Number 
Table 1. Number of claw health records and number of Norwegian Red sires with genotype and informative daughters (claw health records, foot and leg conformation scores or both) for each combination of corkscrew claw (CSC), infectious claw disorder (INF), laminitis-related claw disorder (LAM), hoof quality (HQ), foot angle (FANG), rear leg rear view new (RLRV_N), and rear leg rear view old (RLRV_O)

\begin{tabular}{|c|c|c|c|c|c|c|c|}
\hline Item & $\mathrm{CSC}$ & INF & LAM & HQ & FANG & RLRV_N & RLRV_O \\
\hline \multicolumn{8}{|c|}{ Claw health records (no.) } \\
\hline CSC & 281,835 & 281,835 & 281,835 & 25,598 & 25,598 & 11,803 & 13,795 \\
\hline INF & & 281,835 & 281,835 & 25,598 & 25,598 & 11,803 & 13,795 \\
\hline HQ & & & & 305,195 & 305,195 & 52,330 & 252,865 \\
\hline FANG & & & & & 421,319 & 52,330 & 368,834 \\
\hline RLRV_N & & & & & & 52,330 & 0 \\
\hline $\mathrm{CSC}$ & 1,093 & & & & & & \\
\hline INF & 1,093 & 1,093 & & & & & \\
\hline LAM & 1,093 & 1,093 & 1,093 & & & & \\
\hline HQ & 1,093 & 1,093 & 1,093 & 2,183 & & & \\
\hline FANG & 1,093 & 1,093 & 1,093 & 2,183 & 3,111 & & \\
\hline RLRV_N & 447 & 447 & 447 & 571 & 571 & 571 & \\
\hline RLRV_O & 816 & 816 & 816 & 1,782 & 2,710 & 170 & 2,710 \\
\hline
\end{tabular}

of records for each combination of claw disorders and foot and leg conformation traits is given in Table 1.

SNP Data Set. An imputed 25K/54K SNP data set was available for the analyses. Not all SNP included in the $25 \mathrm{~K}$ SNP chip are in the $54 \mathrm{~K}$ SNP chip, so to exploit all available SNP, the data set was imputed from $25 \mathrm{~K}$ to $54 \mathrm{~K}$ and vice versa. For details of the imputation, refer to Solberg et al. (2011). After standard editing (removal of animals with an individual call rate $<97 \%$, deletion of Mendelian errors for animals with known parents, removal of SNP with Mendelian error rate $>2.5 \%$, deletion of SNP with a call rate $<25 \%$, and removal of SNP with minor allele frequency $<0.05$ ), the data set contained 48,249 SNP for a total of 3,768 Norwegian Red AI sires. Sires with genotype and informative daughters (with data on claw disorders, foot and leg conformation traits, or both) were included in the analyses. Numbers of sires for each trait combination are given in Table 1.

\section{Statistical Analyses}

Three sets of trait combinations were analyzed: (1) CSC, INF, and LAM (CH); (2) CSC, INF, LAM, HQ, and FANG (CF1); and (3) CSC, INF, LAM, RLRV_N, and RLRV_O (CF2). Because of convergence issues it was not possible to analyze all the claw disorders and foot and leg conformation traits together.

$\boldsymbol{E} \boldsymbol{B} \boldsymbol{V}$. Breeding values for CSC, INF, and LAM were predicted using a linear sire model including effects as described in Ødegård et al. (2013). The model in matrix notation was

$$
\mathbf{y}=\mathbf{X} \boldsymbol{\beta}+\mathbf{Z}_{\mathbf{h}} \mathbf{h}+\mathbf{Z}_{\mathbf{s}} \mathbf{s}+\mathbf{e},
$$

where $\mathbf{y}$ is a vector of observations on the trait, $\boldsymbol{\beta}$ is a vector of systematic effects, $\mathbf{h}$ is a vector of random herd effects, $\mathbf{s}$ is a vector of sire effects, $\mathbf{e}$ is a vector of residuals, and $\mathbf{X}, \mathbf{Z}_{\mathbf{h}}$, and $\mathbf{Z}_{\mathrm{s}}$ are the corresponding incidence matrices. The systematic effects were parity with 4 classes, where the fourth class included parity 4 to 13 ; year and month of calving with 119 classes; time of claw trimming (in months after calving) with 12 classes; and claw trimmer with 4 classes: (1) professional claw trimmer, (2) other claw trimmer, (3) farmer, and (4) other person (e.g., veterinarian). The herd effects included 6,976 levels.

Breeding values for HQ, FANG, RLRV_N, and RLRV_O were predicted using a linear sire model including effects described in the study by Ødegård et al. (2014a). The model in matrix notation was

$$
\mathbf{y}=\mathbf{X} \boldsymbol{\beta}+\mathbf{Z}_{\mathrm{hy}} \mathbf{h y}+\mathbf{Z}_{\mathrm{s}} \mathbf{s}+\mathbf{e},
$$

where $\mathbf{y}$ is a vector of observations of the trait; $\boldsymbol{\beta}$ is a vector of systematic effects including year and month of calving, time from calving (months) and time from milking (hours) to scoring, and age at scoring (in months); hy is a vector of random herd-year effects; $\mathbf{s}$ is a vector of sire effects; $\mathbf{e}$ is a vector of residuals; and $\mathbf{X}$, $\mathbf{Z}_{\mathrm{hy}}$, and $\mathbf{Z}_{\mathrm{s}}$ are the corresponding incidence matrices. Year and month of calving had 216 levels for HQ, 315 levels for FANG, 51 levels for RLRV_N, and 275 levels for RLRV_O; time from calving (months) and time from milking (hours) to scoring had 96 levels for HQ, FANG, RLRV_N, and RLRV_O; and age at scoring (in months) had 7 levels for HQ, FANG, RLRV_N, and RLRV_O. The herd-year effect included 98,820 levels for HQ; 149,249 levels for FANG; 12,661 for RLRV_N; and 136,566 for RLRV_O. 
The 3 data sets were analyzed using multivariate models with (co) variances: $\operatorname{var}(\mathbf{h})=\mathbf{H} \otimes \mathbf{I}, \operatorname{var}(\mathbf{h y})$ $=\mathbf{H Y} \otimes \mathbf{I}, \operatorname{var}(\mathbf{s})=\mathbf{G}_{\mathbf{0}} \otimes \mathbf{A}$, and $\operatorname{var}(\mathbf{e})=\mathbf{R} \otimes \mathbf{I}$, where $\mathbf{H}$ is the $3 \times 3$ herd (co)variance matrix; $\mathbf{H Y}$ is the $2 \times 2$ herd-year variance matrix (co-variances were assumed to be zero); $\mathbf{A}$ is the additive genetic relationship matrix; $\mathbf{I}$ are identity matrices; and $\mathbf{G}_{0}$ and $\mathbf{R}$ are the $3 \times 3,5 \times 5$, and $5 \times 5$ corresponding genetic and residual (co)variance matrices for the data sets $\mathrm{CH}, \mathrm{CF} 1$, and $\mathrm{CF} 2$, respectively. The residual covariance between RLRV_N and RLRV_O was assumed zero, because no cows had observation on both traits. The pedigrees of sires were traced as far as possible, resulting in a pedigree file of 15,172 animals for $\mathrm{CH}$ and 26,120 animals for CF1 and CF2.

Deregressed Proofs. To calculate deregressed proofs (DRP; Lidauer and Strandén, 1999; Vuori et al., 2006), the EBV was used as the response variable and the residuals were weighted by effective daughter contribution (Fikse and Banos, 2001) calculated from reliabilities of EBV.

Genomic Breeding Values. Genomic breeding values were predicted using GBLUP (Meuwissen et al., 2001). Deregressed proofs were used as response variables for genomic predictions. The model in matrix notation was

$$
\mathbf{y}=1 \mu+\mathrm{Zg}+\mathbf{e},
$$

where $\mathbf{y}$ is a vector of DRP, $\mathbf{1}$ is a vector of ones, $\boldsymbol{\mu}$ is the overall mean, $\mathbf{g}$ is a vector of genomic effects, $\mathbf{Z}$ is the incidence matrix of $\mathbf{g}$, and $\mathbf{e}$ is a vector of residuals. It was assumed that $\operatorname{var}(\mathbf{g})=\mathbf{G}_{\mathbf{0}} \otimes \mathbf{G}$ and $\operatorname{var}(\mathbf{e})=\mathbf{R}$ $\otimes \mathbf{D}$, where $\mathbf{G}$ is the genomic relationship matrix; $\mathbf{D}$ is a diagonal matrix containing weighting factors for the residuals; and $\mathbf{G}_{0}$ and $\mathbf{R}$ are the $3 \times 3,5 \times 5$, and $5 \times$ 5 corresponding genetic and residual (co)variance matrices for $\mathrm{CH}, \mathrm{CF} 1$, and $\mathrm{CF} 2$, respectively. The residual covariances between claw disorders and foot and leg conformation traits in $\mathrm{CF} 1$ and $\mathrm{CF} 2$ were set to zero. The residuals were weighted by reliabilities of EBV. The inverse G-matrix used in prediction of GEBV was obtained using the G-matrix package ( $\mathrm{Su}$ and Madsen, 2012) and consisted of 1,093 sires in $\mathrm{CH}$ and 3,111 sires in $\mathrm{CF} 1$ and $\mathrm{CF} 2$.

Predictive Correlation of GEBV. Predictive correlation of GEBV was calculated as the correlation between GEBV and DRP. The DRP was calculated from EBV predicted with all available information for each of the 3 data sets (CH, CF1, and CF2).

10-Fold Cross-Validation. A 10-fold cross-validation $(\mathbf{C V a l})$ was performed to assess predictive correlations of GEBV for CSC, INF, and LAM from the data sets CH, CF1, and CF2. The 1,093 sires with daughter information on claw health were randomly assigned to 10 groups, including 109 or 110 sires. Therefore, a sire was only represented in one group. In the CVal, one group was used as the validation set and the remaining 9 constituted the reference population. Sires having daughters with only foot and leg conformation scores were included in the reference population. The reference populations consisted of 983(984), 3,001(3,002), and $3,001(3,002)$ sires for the data sets $\mathrm{CH}, \mathrm{CF} 1$, and CF2, respectively.

Validation by Youngest Sires. An additional validation set (VAL) consisting of the youngest sires having daughters with claw health information was analyzed. This validation set included 190 sires (born in 2007, 2008, and 2009), and the reference populations (sires born before 2007) consisted of 903, 2,797, and 2,797 sires for $\mathrm{CH}, \mathrm{CF} 1$, and $\mathrm{CF} 2$, respectively.

The DMU software (Madsen and Jensen, 2010) was used to estimate (co)variances and predict EBV and GEBV. (Co)variances estimated from the full data sets were used in prediction of EBV for each of the reference populations in CVal and VAL. Estimated heritabilities and genetic correlations are given in Table 2. The MiX99 software (Lidauer and Strandén, 1999; Vuori et al., 2006) was used to calculate DRP and reliabilities of EBV.

\section{RESULTS AND DISCUSSION}

\section{Predictive Correlation of GEBV}

10-Fold Cross-Validation. The mean predictive correlations of GEBV for CSC, INF, and LAM were low, varying from 0.27 to 0.37 (Table 3 ). The mean predictive correlation of GEBV increased slightly, from 0.35 to 0.37 , for $\mathrm{CSC}$ when including $\mathrm{HQ}$ and FANG as correlated traits (CF1), whereas including RLRV_N and RLRV_O (CF2) slightly decreased the mean predictive correlation of GEBV. Including foot and leg conformation traits (CF1 and CF2) decreased the mean predictive correlations of GEBV for INF and LAM compared with using $\mathrm{CH}$ (Table 3). The results suggest that these genetically correlated traits may introduce more noise than additional information to the prediction of GEBV. This may be because few cows had records on both claw disorders and foot and leg conformation traits (Table 1) and the genetic correlations among these traits were in general low (Table 2). The standard deviation of predictive correlations of GEBV ranged from 0.06 to 0.13 among the traits and data sets (Table 3), showing relatively large variation among the folds (Figure 1). The highest standard deviation 
Table 2. Estimated heritability of corkscrew claw (CSC), infectious claw disorder (INF), laminitis-related claw disorder (LAM), hoof quality (HQ), foot angle (FANG), rear leg rear view new (RLRV_N), and rear leg rear view old (RLRV_O) and their genetic correlation (SE) to claw disorders

\begin{tabular}{lcrrr}
\hline & & \multicolumn{3}{c}{ Genetic correlation } \\
\cline { 3 - 5 } Trait & Heritability & \multicolumn{1}{c}{ CSC } & \multicolumn{1}{c}{ INF } & LAM \\
\hline CSC & 0.06 & $0.09(0.07)$ & & \\
INF & 0.03 & $0.26(0.06)$ & $0.25(0.08)$ & \\
LAM & 0.03 & $-0.79(0.04)$ & $-0.09(0.07)$ & $-0.27(0.07)$ \\
HQ & 0.03 & $0.08(0.05)$ & $0.10(0.06)$ & $0.11(0.06)$ \\
FANG & 0.09 & $0.03(0.08)$ & $-0.09(0.09)$ & $0.15(0.09)$ \\
RLRV_N & 0.08 & $0.14(0.06)$ & $-0.02(0.07)$ & $0.14(0.07)$ \\
RLRV_O & 0.07 & & &
\end{tabular}

for CSC, INF, and LAM occurred using CF2, which had the lowest mean predictive correlation of GEBV and lowest number of cows with records on both claw disorders and foot and leg conformation traits (Table 1). All mean predictive correlations of GEBV for CSC, INF, and LAM using CF1 and CF2 were within the range of one standard deviation of the mean predictive correlation of GEBV using the data set $\mathrm{CH}$. The overall best result for CSC was obtained using data set CF1 (Figure 1), whereas for INF it was obtained using data set $\mathrm{CH}$ (Figure 1). For LAM, data sets $\mathrm{CH}$ and $\mathrm{CF} 1$ gave very similar results over all folds (Figure 1). The large differences in predictive correlations of GEBV among validation sets in CVal could be due to unequal amount of information for sires in the validation set or differences in the relationship of a sire to the reference population. By using CVal, and randomly assign sires in groups, some sires in a validation set may be older, elite sires having sons with information in the reference population, and thereby gaining a lot of information in the CVal compared with young sires with less data. This could lead to overestimation of predictive correlation of GEBV; therefore, an additional validation set including the youngest sires was analyzed.

Validation by Youngest Sires. Including foot and leg conformation traits increased the predictive correlation of GEBV for CSC in VAL (Table 4), and the highest correlation was achieved using the data set
CF1 (0.49), which included HQ that had strong genetic correlation to CSC (Table 2). For INF the predictive correlation of GEBV was 0.33 to 0.34 in all 3 data sets, whereas for LAM the predictive correlation of GEBV decreased when including foot and leg conformation traits (Table 4). The predictive correlations of GEBV for INF and LAM from VAL (Table 4) were within the range of values found in CVal (Table 3). For CSC the predictive correlations of GEBV from $\mathrm{CF} 1$ and $\mathrm{CF} 2$ were above the maximum value in CVal. Infectious claw disorder had low genetic correlation with foot and leg conformation traits (Table 2) and was, therefore, expected to benefit less from including these as correlated traits in genomic prediction. This is reflected by the results, where INF had the lowest predictive correlation of GEBV among the claw disorders and no gain from correlated traits. The predictive correlations of GEBV for CSC, INF, and LAM from validation based on the youngest sires were similar as those obtained in CVal, indicating that overestimation was not a problem in this study. A benefit of using CVal, compared with VAL, was the obtained variance of the predictive correlation of GEBV, which is a measure of precision.

It was beneficial to include the foot and leg conformation traits $\mathrm{HQ}$ and FANG in genomic predictions for CSC, whereas for INF and LAM including foot and leg conformation traits introduced more noise than additional information. Ødegård et al. (2014b) calculated

Table 3. Mean, SD, minimum value (Min), and maximum value (Max) of predictive correlation of genomic breeding values (GEBV) for corkscrew claw (CSC), infectious claw disorder (INF), and laminitis-related claw disorder (LAM) from a 10 -fold cross-validation ${ }^{1}$

\begin{tabular}{|c|c|c|c|c|c|c|c|c|c|c|c|c|}
\hline Data set & \multicolumn{4}{|c|}{$\mathrm{CSC}$} & \multicolumn{4}{|c|}{ INF } & \multicolumn{4}{|c|}{ LAM } \\
\hline CF2 & 0.31 & 0.10 & 0.15 & 0.42 & 0.27 & 0.13 & 0.00 & 0.53 & 0.29 & 0.07 & 0.16 & 0.36 \\
\hline
\end{tabular}

${ }^{1}$ Correlation between GEBV and deregressed proofs from multivariate models using 3 data sets: $\mathrm{CH} 1, \mathrm{CF} 1$, and $\mathrm{CF} 2$. CH $=$ data set including CSC, INF, and LAM; CF1 = data set including CSC, INF, LAM, hoof quality, and foot angle; CF2 = data set including CSC, INF, LAM, rear leg rear view new, and rear leg rear view old. 
Table 4. Predictive correlation of genomic breeding values (GEBV) for corkscrew claw, infectious claw disorder, and laminitis-related claw disorder from validation by the 190 youngest sires $^{1}$

\begin{tabular}{lccc}
\hline Item & CH & CF1 & CF2 \\
\hline Corkscrew claw & 0.38 & 0.49 & 0.43 \\
Infectious claw disorder & 0.33 & 0.34 & 0.33 \\
Laminitis-related claw disorder & 0.41 & 0.36 & 0.36 \\
\hline
\end{tabular}

${ }^{1}$ Correlation between GEBV and deregressed proofs from multivariate models using 3 data sets: $\mathrm{CH}, \mathrm{CF} 1$, and $\mathrm{CF} 2$. $\mathrm{CH}=$ data set including corkscrew claw, infectious claw disorder, and laminitis-related claw disorder; $\mathrm{CF} 1$ = data set including corkscrew claw, infectious claw disorder, laminitis-related claw disorder, hoof quality, and foot angle; $\mathrm{CF} 2$ = data set including corkscrew claw, infectious claw disorder laminitis-related claw disorder, rear leg rear view new and rear leg rear view old.

\section{Corkscrew claw}

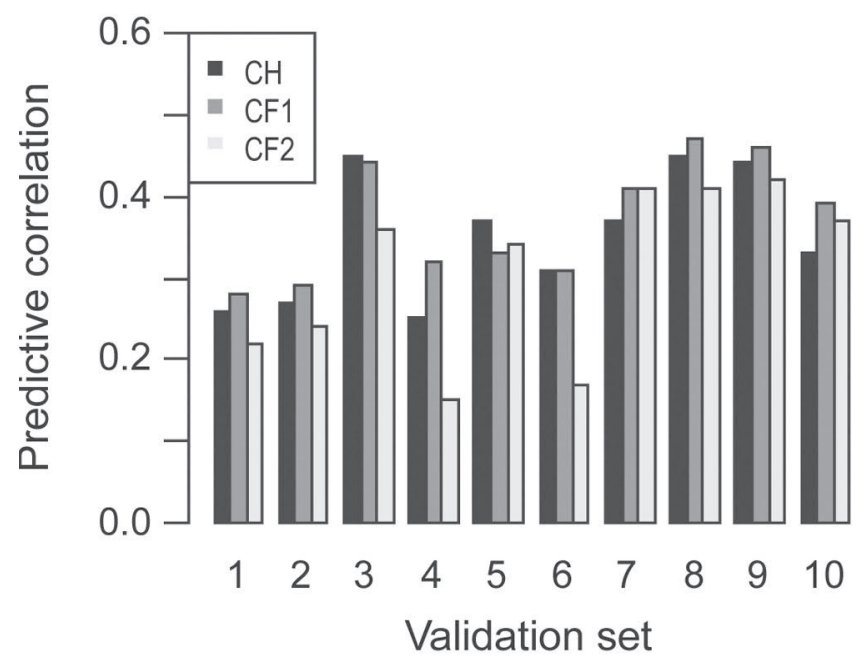

\section{Laminitis-related claw disorder}

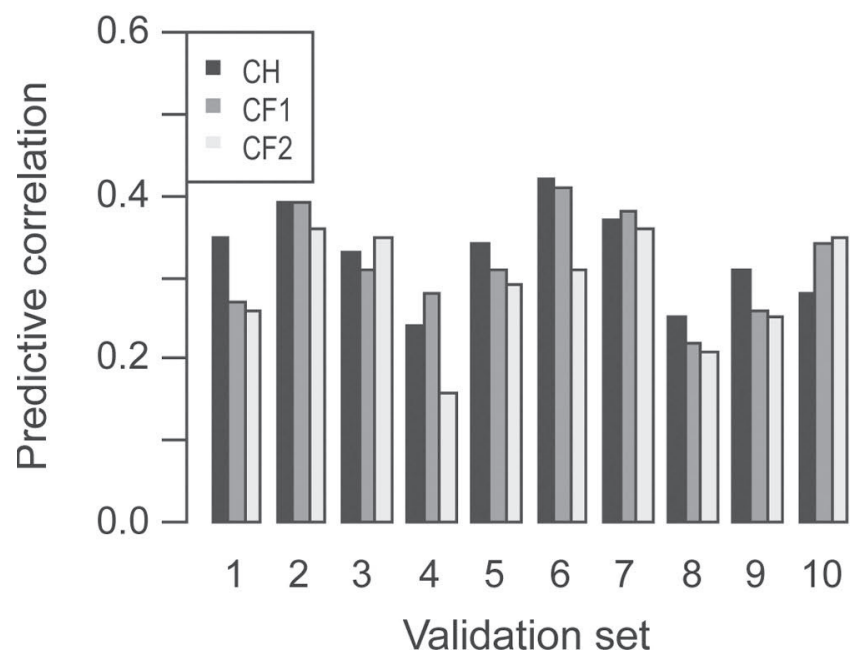

the predictive ability of GEBV (correlation between GEBV and daughter yield deviation) for CSC in a univariate (0.29) and bivariate model (0.32), including CSC and HQ, showing similar results as in the present study. The higher predictive correlation of GEBV for CSC found in the present study (Tables 3 and 4) compared with the findings of Ødegård et al. (2014b) could be due to different response variables and additional traits included in the analyses. Karoui et al. (2012) showed that accuracy of GEBV increased slightly in small breeds when highly genetic correlated traits from larger breeds were included in the analyses. The low genetic correlation among most of the claw disorders and

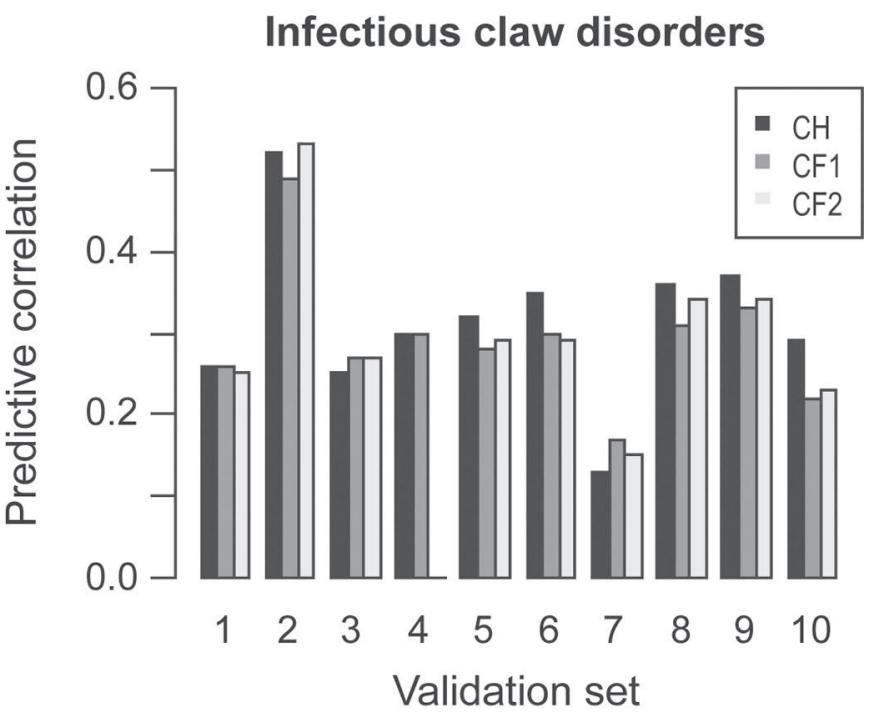

Figure 1. Predictive correlations of genomic breeding values (GEBV) for corkscrew claw (CSC), infectious claw disorder (INF), and laminitis-related claw disorder (LAM) from 10-fold cross-validation using 3 data sets: CH (CSC, INF, and LAM); CF1 (CSC, INF, LAM, hoof quality, and foot angle); and CF2 (CSC, INF, LAM, rear leg rear view new, and rear leg rear view old). 
foot and leg conformation traits (Table 2) could explain the small effect on predictive correlation of GEBV in the present study. Buitenhuis et al. (2007) detected 4 QTL associated with lameness (group of claw disorders), and these had small overlap with QTL found for foot and leg conformation traits. This indicates that different genes affect claw disorders and foot and leg conformation traits, which is also consistent with the low genetic correlations among these traits (e.g., van der Waaij et al., 2005; Ødegård et al., 2014a).

The accuracy of GEBV for other low-heritability traits in Norwegian Red (e.g., Solberg et al., 2011; Svendsen et al., 2013; Haugaard et al., 2014) were in the same range as the predictive correlation of GEBV calculated in the present study. Haugaard et al. (2014) found accuracy of genomic predictions (correlation between EBV and GEBV) for 4 fertility-related disorders in Norwegian Red ranging from 0.17 to 0.65 . In Norwegian Red, correlations between GEBV and EBV were predicted for milk production traits to be around 0.6, whereas for health and fertility traits the correlations ranged from 0.2 to 0.4 (Svendsen et al., 2013). Similar results were found in other breeds (e.g., Karoui et al., 2012; Pintus et al., 2013; Zhou et al. 2014), where the accuracy of GEBV was lowest for low-heritable traits. Despite the limited historical data and the small reference population available for claw disorders, the predictive correlations of GEBV for CSC, INF, and LAM were in the same range as accuracies of GEBV obtained for other low-heritable traits in Norwegian Red.

\section{Increasing the Predictive Correlation of GEBV}

Claw disorders are novel traits with limited historical data and therefore fewer animals in the reference population. Including foot and leg conformation traits had little or no effect on the predictive correlations of GEBV for CSC, INF, and LAM, despite the increased number of sires in the reference population. This could partly be because most sires had few daughters with claw health information (average 168, minimum 30) and few cows had information on both claw health and foot and leg conformation score. The high effective population size in Norwegian Red (Geno, 2013) and the low genetic correlations among the traits also affected the results. Better predictive correlations of GEBV could possibly be obtained by increasing the number of animals in the reference population, increasing the number of phenotypic records (claw health records), and by genotyping of cows.

Genomic predictions across breeds and populations is one approach to obtain larger reference populations (e.g., Brøndum et al., 2011; Heringstad et al., 2011; Lund et al., 2011) and thereby increase predictive cor- relation of GEBV. Reliabilities of GEBV for Norwegian Red calculated in a joint Nordic reference population (including Norwegian Red, Swedish Red, Finnish Ayrshire, and Danish Red) increased slightly for production traits compared with a reference population consisting of only Norwegian Red. However, for health traits reliability did not increase, and for fertility traits the reliability of GEBV decreased (Heringstad et al., 2011). Lund et al. (2011) showed increased reliability of genomic prediction using a common reference population within breed, and Hozé et al. (2014) found increased gain in accuracy of genomic evaluation methods using a multibreed reference population in a small breed where bulls had missing sires in the reference population. The results in these studies varied among breeds and populations, which partly could be explained by variation in relationship among animals, as confirmed by Brøndum et al. (2011), who concluded that reliabilities of direct breeding values increased when strong genetic links between animals in a multibreed reference population were present.

The number of yearly claw health records has increased since national recording started in 2004, to approximately 70,000 records per year. There is, however, a huge potential to further increase the recording of claw health in Norway; only $33 \%$ of the herds recorded claw health at claw trimming in 2013. Number of daughters with claw health records for the 1,093 Norwegian Red sires in the present study varied from 30 to 6,524 , and reliabilities of their EBV for CSC, INF, and LAM varied from 0.20 to 0.99 . Mean reliability of EBV for CSC increased from 0.67 (using $\mathrm{CH}$ and $\mathrm{CF} 1$ ) to 0.72 using CH1, whereas for INF and LAM it did not change between the 3 data sets. The increased reliability of EBV for CSC using CF1 can be explained by more informative daughters available for analyses, because of the strong genetic correlation between CSC and HQ. In the present analyses only sires having at least 30 daughters with information were included, whereas in routine genetic evaluations most sires have less than 30 daughters with claw health records at the time of their first official proof. However, claw health information from more herds can contribute with more information per sire and increased reliability of EBV, and thereby improved phenotypes for genomic prediction.

Genotyping of females to be included in the reference population is another possibility to increase the predictive correlation of GEBV. Several studies have shown that genotyping of females is beneficial in genomic predictions (e.g., Mc Hugh et al., 2011; Pryce et al., 2012; Egger-Danner et al., 2014), especially in breeds with small reference populations or for novel traits. In a study where the reference population consisted of genotyped cows with phenotypic records on new traits, 
including genotyped bulls in the reference population with records on a positive genetic correlated index increased the accuracy of selection (Calus et al., 2013). Egger-Danner et al. (2014) stated that for novel traits, the reliability of GEBV would increase if genotyped cows with reliable phenotypes were added to a small reference population, because bulls in the reference population would have few daughters with records on the novel traits and thereby less reliable GEBV. For claw disorders in Norwegian Red, it might be beneficial to genotype cows with claw health records to increase the reference population and thereby improve genomic predictions.

This was the first genomic analyses of claw disorders in Norwegian Red. Although claw disorders are novel traits with limited historical data and a small reference population, the predictive correlations of GEBV for CSC, INF, and LAM were in the same range as for other health traits in Norwegian Red. Further increase in predictive correlation of GEBV may be achieved by getting more herds to record claw health and by genotyping cows to be included in the reference population.

\section{CONCLUSIONS}

The predictive correlations of GEBV for CSC, INF, and LAM were in general low, and including genetically correlated foot and leg conformation traits had little or no effect, despite the increased reference population. The predictive correlation of GEBV for CSC increased slightly when including $\mathrm{HQ}$ and FANG, whereas for other traits a small decrease were observed when including the correlated traits. The results illustrate the challenges related to genomic selection of novel traits with limited historical data and a small reference population. Including traits with strong genetic correlation may have some slight, positive influence on the predictive correlation of GEBV.

\section{ACKNOWLEDGMENTS}

The authors thank the Norwegian Dairy Herd Recording System (Ås, Norway) and the Norwegian Cattle Health Service (Ås, Norway) for access to data; Geno SA (Hamar, Norway) for access to SNP data; Harald Grove, Cigene, Norwegian University of Life Sciences (NMBU), for imputation of SNP data; and the Norwegian Research Council (Oslo, Norway) and Geno SA for funding (project 212864).

\section{REFERENCES}

Brøndum, R. F., E. Rius-Vilarrasa, I. Strandén, G. Su, B. Guldbrandtsen, W. F. Fikse, and M. S. Lund. 2011. Reliabilities of genomic prediction using combined reference data of the Nordic Red dairy cattle populations. J. Dairy Sci. 94:4700-4707.

Bruijnis, M. R. N., B. Beerda, H. Hogeveen, and E. N. Stassen. 2012. Assessing the welfare impact of foot disorders in dairy cattle by modeling approach. Animal 6:962-970.

Bruijnis, M. R. N., H. Hogeveen, and E. N. Stassen. 2010. Assessing economic consequences of foot disorders in dairy cattle using a dynamic stochastic simulation model. J. Dairy Sci. 93:2419-2432.

Buch, L. H., A. C. Sørensen, J. Lassen, P. Berg, J.-A. Eriksson, J. H. Jakobsen, and M. K. Sørensen. 2011. Hygiene-related and feedrelated hoof diseases show different patterns of genetic correlations to clinical mastitis and female fertility. J. Dairy Sci. 94:1540-1551.

Buitenhuis, A. J., M. S. Lund, J. R. Thomasen, B. Thomsen, V. Hunnicke Nielsen, C. Bendixen, and B. Guldbrandtsen. 2007. Detection of quantitative trait loci affecting lameness and leg conformation traits in Danish Holstein cattle. J. Dairy Sci. 90:472-481.

Calus, M. P. L., Y. de Haas, M. Pszczola, and R. F. Veerkamp. 2013. Predicted accuracy of and response to genomic selection for new traits in dairy cattle. Animal 7:183-191.

Egger-Danner, C., H. Schwarzenbacher, and A. Willam. 2014. Short communication: Genotyping of cows to speed up availability of genomic estimated breeding values for direct health traits in Austrian Fleckvieh (Simmental) cattle-Genetic and economic aspects. J. Dairy Sci. 97:4552-4556.

Fikse, W. F., and G. Banos. 2001. Weighting factors of sire daughter information in international genetic evaluations. J. Dairy Sci $84: 1759-1767$

Gao, H., M. S. Lund, Y. Zhang, and G. Su. 2013. Accuracy of genomic prediction using different models and response variables in the Nordic Red cattle population. J. Anim. Breed. Genet. 130:333340 .

Geno. 2013. Årsberetning og regnskap 2013. Page 13. Accessed Feb. 10, 2015. http://viewer.zmags.com/publication/d5a081bc\#/ d5a081bc/1. (In Norwegian).

Haugaard, K., M. Svendsen, and B. Heringstad. 2014. Genomic predictions of fertility related disorders in Norwegian Red using 30 years of data. Proc. 10th World Congr. Genet. Appl. Livest. Prod. (WCGALP), Vancouver, Canada. Accessed Mar. 17, 2015. https:// asas.org/docs/default-source/wcgalp-proceedings-oral/309_paper_9024_manuscript_368_0.pdf?sfvrsn=2.

Hayes, B. J., P. J. Bowman, A. J. Chamberlain, and M. E. Goddard. 2009. Invited review: Genomic selection in dairy cattle: Progress and challenges. J. Dairy Sci. 92:433-443.

Heringstad, B., G. Su, T. R. Solberg, B. Guldbrantsen, M. Svendsen, and M. S. Lund. 2011. Genomic predictions based on a joint reference population for Scandinavian Red breeds. Page 29 in Proc. 62th Eur. Fed. Anim. Sci. (EAAP) Annu. Mtg., Stavanger, Norway. Wageningen Academic Publishers, Wageningen, the Netherlands.

Hozé, C., S. Fritz, F. Phocas, D. Boichard, V. Ducrocq, and P. Croiseau. 2014. Efficiency of multi-breed genomic selection for dairy cattle breeds with different sizes of reference population. J. Dairy Sci. 97:3918-3929

Karoui, S., M. J. Carabaño, C. Díaz, and A. Legarra. 2012. Joint genomic evaluation of French dairy cattle breeds using multiple-trait models. Genet. Sel. Evol. 44:39.

Lidauer, M., and I. Strandén. 1999. Fast and flexible program for genetic evaluation in dairy cattle. International workshop in high performance computing and new statistical methods in dairy cattle breeding, Tuusula, Finland. Interbull Bull. 20:20-25.

Luan, T., J. A. Woolliams, S. Lien, M. Kent, M. Svendsen, and T. H. E. Meuwissen. 2009. The accuracy of genomic selection in Norwegian Red cattle assessed by cross-validation. Genetics 183:1119-1126.

Lund, M. S., A. P. W. de Roos, A. G. de Vries, T. Druet, V. Ducrocq, S. Fritz, F. Guillaume, B. Guldbrandtsen, Z. Liu, R. Reents, C. Schrooten, F. Seefried, and G. Su. 2011. A common reference population from four European Holstein populations increases reliability of genomic predictions. Genet. Sel. Evol. 43:43.

Madsen, P., and J. Jensen. 2010. A User's Guide to DMU. A Package for Analysing Multivariate Mixed Models. Version 6, release 5.0. 
Faculty Agric. Sci. (DJF), Dept. Genet. Biotechnol., Univ. Aarhus, Res. Center Foulum, Tjele, Denmark.

Mc Hugh, N., T. H. E. Meuwissen, A. R. Cromie, and A. K. Sonesson. 2011. Use of female information in dairy cattle genomic breeding programs. J. Dairy Sci. 94:4109-4118.

Meuwissen, T. H. E., B. J. Hayes, and M. E. Goddard. 2001. Prediction of total genetic value using genome-wide dense marker maps. Genetics 157:1819-1829.

Ødegård, C., M. Svendsen, and B. Heringstad. 2013. Genetic analyses of claw health in Norwegian Red cows. J. Dairy Sci. 96:7274-7283.

Ødegård, C., M. Svendsen, and B. Heringstad. 2014a. Genetic correlations between claw health and feet and leg conformation in Norwegian Red cows. J. Dairy Sci. 97:4522-4529.

Ødegård, C., M. Svendsen, and B. Heringstad. 2014b. Predictive ability of genomic breeding values for corkscrew claw in Norwegian Red. Proc. 10th World Congr. Genet. Appl. Livest. Prod. (WCGALP), Vancouver, Canada. Accessed Mar. 17, 2015. https:// asas.org/docs/default-source/wcalp-proceedings-oral/300_paper_9013_manuscript_362_0.pdf?sfvrsn=2.

Pintus, M. A., E. L. Nicolazzi, J. B. C. H. M. Van Kaam, S. Biffani, A. Stella, G. Gaspa, C. Dimauro, and N. P. P. Macciotta. 2013. Use of different statistical models to predict direct genomic values for productive and functional traits in Italian Holsteins. J. Anim. Breed. Genet. 130:32-40.

Pryce, J. E., B. J. Hayes, and M. E. Goddard. 2012. Genotyping dairy females can improve the reliability of genomic selection for young bulls and heifers and provide farmers with new management tools. Proc. Int. Comm. Anim. Rec. (ICAR), Cork, Ireland. Accessed Mar. 17, 2015. http://www.icar.org/cork_2012/.

Sogstad, Å. M., O. Østerås, and T. Fjeldaas. 2006. Bovine claw and limb disorders related to reproductive performance and production diseases. J. Dairy Sci. 89:2519-2528.

Sogstad, A.. M., O. Østerås, T. Fjeldaas, and A. O. Refsdal. 2007. Bovine claw and limb disorders at claw trimming related to milk yield. J. Dairy Sci. 90:749-759.
Solberg, T. R., B. Heringstad, M. Svendsen, H. Grove, and T. H. E. Meuwissen. 2011. Genomic predictions for production and functional traits in Norwegian Red from BLUP analyses of imputed 54K and 777K SNP data. Interbull Bull. 44:240-243.

Su, G., and P. Madsen. 2012. User's Guide for Gmatrix. A Program for Computing Genomic Relationship Matrix. Dept. Genetics, Dept. Biotechnology, Aarhus Univ., Tjele, Denmark.

Svendsen, M., B. Heringstad, and T. R. Solberg. 2013. Bruk av genomisk avlsverdi ved innkjøp av seminokseemner i NRF avlen. Husdyrfors $\varnothing$ ksm $\varnothing$ te. Lillestrøm, Norway. (In Norwegian).

Swalve, H. H., H. Alkhoder, and R. Pijl. 2008. Estimates of breeding values for sires based on diagnoses recorded at hoof trimming: Relationships with EBV for conformation traits. Interbull Bull. 38:87-90.

Uggla, E., J. H. Jakobsen, C. Bergsten, J.-A. Eriksson, and E. Strandberg. 2008. Genetic correlations between claw health and feet and leg conformation traits in Swedish dairy cows. Interbull Bull. 38:91-95.

van der Waaij, E. H., M. Holzhauer, E. Ellen, C. Kamphuis, and G. de Jong. 2005. Genetic parameters for claw disorders in Dutch dairy cattle and correlations with conformation traits. J. Dairy Sci. 88:3672-3678.

Vuori, K., I. Strandén, M. Lidauer, and E. A. Mäntysaari. 2006. MiX99-Effective solver for large and complex linear models. Pages 27-33 in Proc. 8th World Congr. Genet. Appl. Livest. Prod. (WCGALP), Belo Horizonte, MG, Brazil.

Zhou, L., B. Heringstad, G. Su, B. Guldbrandtsen, T. H. E. Meuwissen, M. Svendsen, H. Grove, U. S. Nielsen, and M. S. Lund. 2014. Genomic predictions based on a joint reference population for the Nordic Red cattle breeds. J. Dairy Sci. 97:4485-4496. 